Илдико Палоши

Университет им. Лоранда Этвеша, Будапешт Филологический факультет

Кафедра русского языка и литературы

palosi.ildiko@btk.elte.hu
УДК 811.161.1'367.625'37

https://doi.org/10.18485/slavistika.2019.23.1.4

оригинални научни рад примљено 12.05.2019.

прихваћено за штампу 16.05.2019.

\title{
СЕМАНТИЧЕСКИЙ АНАЛИЗ ГЛАГОЛОВ СО ЗНАЧЕНИЕМ БЫСТРОГО ДЕЙСТВИЯ В РУССКОМ ЯЗЫКЕ
}

Настоящая статья посвящена семантическому анализу глаголов с семой ‘быстро’. В работе представляются возможности грамматикализации данной семы при помощи суффиксов -ну-, -ану- и префикса про-. В цели исследования входит определение семантического отношения между моментальным, одноактным, динамичным (т. е. быстрым) и процессуальным характерами действия.

Ключевые слова: грамматикализация, семельфактив, моментальность, динамичность, процессуальность.

The article is devoted to a semantic analysis of Russian verbs with the seme 'quickly'. It presents varieties of grammaticalization of the given seme by suffixes -nu-, -anu- and a prefix pro-. The study aims to define the semantic relations between momentality, semelfactivity, dynamics (eg. speed) and processuality of actions.

Key words: grammaticalization, semelfactivity, momentality, dynamics, processuality.

\section{Введение}

В настоящей статье рассматриваются глаголы, в семантическую зону которых входит сема быстрого проведения действия. В ходе исследования мы попытаемся найти ответ на следующие вопросы:

1. Какими аффиксами сема ‘быстро’ может грамматикализоваться?

2. С какими семами может сочетаться сема 'быстро' в семантической структуре глаголов?

3. Какая связь между моментальностью и быстрым проведением действия?

Не нуждается в пояснениях, что проявляющаяся в значении некоторых глаголов сема ‘быстро’ тесно связана с наречием быстро, синонимами которого являются стремительно, шибко, бурно, в темпе, быстрыми темпами, пулей, стрелой, вихрем, рысью, скороговоркой, во весь опор, во весь дух, сломя голову; моментально, мгновенно, вмиг, молниеносно, мигом, в один момент, в один миг, в одно мгновение, в мгновение ока, в сжатые сроки, в два счета, внезапно, неожиданно, сразу и т. д. Семантическому описанию данного многозначного наречия посвящены немногочисленные исследования, среди которых можно выделить две работы: (Богуславский, Иомдин 1999) и (Плунгян 2000).

Перед тем как рассмотреть возможности манифестации семы 'быстро' на уровне морфологии, необходимо уделить внимание полисемичной семантике 
наречия 'быстро'. По мнению В. А. Плунгяна можно выделить следующие три основных значения наречия 'быстро':

1. Процессное 'быстро'. Первое значение связано со скоростью, динамичностью, интенсивностью действия. ' $<$ Процесс $\mathrm{P}>$ протекает с большой скоростью', т. е. 'более интенсивно (в единицу времени происходит большее количество Р) по сравнению с нормой'. Ср. быстро бежать 'бежать с большой скоростью’; однако скорость не обязательно связана с движением, ср. быстро читать, работать, одеваться, соображать, развиваться, учить, ухудиаться, повышаться, гореть и др. ${ }^{1}$ Антонимом быстро в этом значении является медленно (Плунгян 2000: 212-213).

(1) Потому как в новом климате осенью, зимой и весной температура то и дело скачет через ноль - то плюс, то минус. А это быстро разрушает материалы (Юлия Смирнова. Прогнозы специалистов по климату: Уже в этом веке в Поволжье будут расти мандарины // Комсомольская правда, 2014.07.31. НКРЯ²)

2. Результативное 'быстро'. Второе значение связано с длительностью ситуации: ситуация продолжается меньше ожидаемого срока, результат процесса наступает раньше ожидаемого срока. Данное значение толкуется следующим образом: '<Естественное завершение процесса $\mathrm{P}>$ наступило за более короткий (по сравнению с ожидаемым или нормальным) промежуток времени', ср. быстро дойти до озера, написать письмо, проверить билеть, найти решение, справиться с задачей, вырасти, разобраться в ситуации и др. Антонимом быстро в этом значении может быть долго (Плунгян 2000: 213-214).

(2) Я себя часто ловлю на мысли, что мне ужасно не нравится, что моя дочка так быстро выросла и хочется ее задержать в детском девченочьем возрасте подольше ... (Наши дети: Подростки (2004) НКРЯ).

3. Реактивное 'быстро': Третье значение связано со скоростью ответной реакции субъекта. Наречием быстро оценивается не длительность протекания ситуации как таковая, а длительность промежутка времени между ситуацией $\mathrm{A}$ и ситуацией Б. При этом ситуация А является прямой или косвенной причиной ситуации Б. Например: он быстро прищел на помощь - ситуация Б; его позвали на помощь - ситуация А. Другие примеры: быстро почувствовать, вернуться, уехать, действовать. Антонимом быстро в этом значении может стать нескоро (Плунгян 2000: 214-215).

(3) 38-летний водитель врезался в другой автомобиль недалеко от города Лоерах на юге Германии, после чего быстро уехал. (Виновник ДТП спросил у полиции, как скрыться (2004) // РИА «Новости», 2004.09.10. НКРЯ).

${ }^{1}$ Примеры в пунктах 1., 2. и 3. отчасти заимствованы из статьи (Плунгян 2000).

${ }^{2}$ Примеры с пометой НКРЯ заимствованы из Национального корпуса русского языка.
Семантический анализ глаголов со значением быстрого действия в русском языке

\section{1. Моментальные глаголы}

Значение быстрого проведения действия входит в семантическую структуру моментальных глаголов. Общеизвестно, что термин «моментальные глаголы» был введен Ю. С. Масловым (1948), а позднее дальнейшие значительные исследования были проведены Ю. Д. Апресяном (1988) и Е. В. Падучевой (1998). Е. В. Падучева моментальными называет глаголы СВ, не имеющие коррелята НСВ в процессуальном значении, напр. очнуться, посnать, найти, уnасть, достичь, выстрелить, посетить и т. д. (Падучева 1998: 332), т. е. моментальные глаголы обозначают действия, которые нельзя представить как длящийся процесс. С точки зрения таксономии к моментальным глаголам относятся происшествия с действующим субъектом. В результате таких действий возникает новое состояние, которое часто не совпадает с целью субъекта: см. глаголы уронить, промахнуться, споткнуться, ошибиться, упустить из виду, забыть и т. д. (Ibid.: 334)

Е. В. Падучева к моментальным глаголам причисляет семельфактивы типа кашлянуть, делимитативы типа посnать, пердуративы типа просидеть, некоторые глаголы начинательного способа действия (в дальнейшем - СД) типа побежать, а также финитивного СД типа отговорить (Ibid.: 337-338).

На наш взгляд, каждый моментальный глагол включает сему ‘быстро’, однако не все глаголы с семой 'быстро’ можно считать моментальными глаголами. Попытаемся доказать данное утверждение на аналитических примерах.

Глаголы в сочетании с наречием 'быстро1' (процессное быстро) часто являются парными глаголами. Коррелят НСВ можно употреблять в процессуальном значении, см. пример (4).

(4) Я слышал, как ты быстро читал доклад.

Однако глаголы в сочетании с наречием результативного 'быстро' не могут передавать длящийся процесс, но способны его подразумевать. В примере (5) речь идет о высокой скорости действия, т. е. мы имеем дело не с 'быстро2', а - с 'быстро1'. Ситуация в примере (6) является политемпоральной, повторяющейся ситуацией, продолжительность действия отодвигается на задний план Значительный интерес представляет пример (7), в котором безусловно можно обнаружить сему 'быстро2', поскольку в фокусе внимания находится результативный характер действия. Ясно, что достижению результата предшествовал процесс, наблюдателем которого стал говорящий от его начала до конца, т. е. процесс проведения действия является ингерентной частью данной ситуации. С одной стороны, форма совершенного вида глагола указывает на то, что акцент ставится на законченности и результативности действия, но с другой стороны в предложении обозначается и продолжительность проведения действия - она представляет собой более короткий промежуток времени, чем говорящий ожидал.

(5) Я видел, как он быстро пишет письмо.

(6) Он быстро пишет письма на английском языке.

(7) Я видел, как он быстро написал письмо. 
Глаголы в сочетании с наречием с семой реактивного 'быстро', как видно по примерам, могут выражать как единичное (пример (8), так и многократное действие (пример (9), но не способны передавать длящийся процесс, см. пример (10). Заметим, что пример (10) является аграмматичным предложением: правильность предложения можно восстановить заменой глагола приходит на глагол идет.

(8) Он быстро пришел на помощь.

(9) Он быстро приходит на помощь.

(10) *Я вижу, как он быстро приходит на помощь.

\section{2. Грамматикализация семы 'быстро'}

Мы присоединяемся к мнению В. А. Плунгяна о том, что на морфологическом уровне сема 'быстро’ наиболее ярко выражается суффиксом -ну- (см глаголы кинуть, прыгнуть, нырнуть, дунуть, глянуть, чихнуть, глотнуть, ругнуть, пугнуть, моргнуть и т. д.). Глаголы с суффиксом -ану- (типа долбануть, рубануть, секануть, драпануть, чесануть, толкануть, пугануть, крутануть, давануть, психануть, резануть, садануть, хлестануть и т. д.) и комбинацией суффикса -ну- с разными префиксами (вз-/вс-, npu-, npo-, c-), см. всплакнуть, прихвастнуть, простирнуть, сболтнуть), В. А. Плунгяном рассматриваются как комплекс глаголов с суффиксом -ну-. Принимая во внимание, что все эти глаголы относятся к семельфактивам, можно согласиться с его подходом.

Семельфактивы с суффиксом -ну-, указывающие на одноактное, мгновенное действие, осуществляемые в один прием. Они соотносительны с мультипликативами, выражают один квант многоактного действия, передаваемого мультипликативным коррелятом (Бондарко, Буланин 1967: 25). Ср.: кидать-кинуть, прыгать-прыгнуть, нырять-нырнуть, чихать-чихнуть, моргать-моргнуть, ахать-ахнуть, зевать-зевнуть, вилять-вильнуть, двигать-двинуть, хлопать-хлопнуть, топать-топнуть, плевать-плюнуть и т. д. Моментальность и неожиданность действия часто подчеркивается обстоятельствами (акциональными показателями) типа вдруг, разом, внезапно, тотчас же, сразу, неожиданно и т. д. (Крекич 1997: 29), см. пример (11).

(11) Но тот вдруг прыгнул и толкнул Максима в кусты (В. Крапивин. Болтик (1976), НКРЯ).

Видовая соотносительность мультипликативов и семельфактивов стала предметом изучения во многих работах (Храковский 1997; 1998; Князев 2004 ; Горбова 2016). Данный вопрос является релевантным для нас по следующим причинам: если семельфактивы могут процессуализироваться, т. е. если семельфактивы и мультипликативы образуют видовую пару и мультипликатив может употребляться в процессуальном значении, то по определению Е. В. Падучевой семельфактивы нельзя считать моментальными глаголами. Вкратце представим некоторые возможности обозначения единичного кванта действия мультипликативными глаголами.
Семантический анализ глаголов со значением быстрого действия в русском языке

Как известно, в русском языке в контекстах настоящего исторического (см. пример (12) и настоящего репортажа (см. пример (13) семельфактив заменяется мультипликативом, т. е. мультипликатив указывает на одноактное действие.

(12) Встречаясь с нашей учительницей младших классов, тихоней, чьи слова мы даже на передних партах различали с трудом, я так и вижу, как она швыряет бананом в классного заводилу и орет: «Оставь меня в покое, бога ради, оставь меня в покое», - и, рыдая, выбегает из класса. Недавно, случайно повстречав одноклассницу, я припомнила этот эпизод - а она его напрочь забыла. (Сесилия Ахерн. Игра в Марблс. НКРЯ).

(13) 13:12 - Спиридонов у сетки выше всех прыгает и вколачивает мяч (Андрей Петухов. Россия неожиданно проиграла Канаде в матче Мировой лиги (текстовая трансляция) // Советский спорт, 2013.07.19. НКРЯ)

В примерах (14)-(15) очевидно, что речь идет о единичном акте, который представляется не как моментальное действие, а как актуальный в момент наблюдения процесс.

(14) Мне попалась случайная картинка, на которой пловец ныряет в воду (Константин Шереметьев. Бешеный креатив. Десятки идей в день $3 а 12$ минут. НКРЯ).

(15) Красноперов усаживается с нею рядом. Софи прыгает ему на колени (Сергей Довлатов. Иная жизнь. НКРЯ).

В зеркале примеров (12)-(15) подвергается сомнению, что моментальный характер действия исключает процессуализацию семельфактивов. Данное наблюдение наводит нас на мысль, что из описанных выше трех значений наречия быстро семельфактивы с суффиксом -ну- включают сему 'быстро1'. В этом убеждает нас и тот интересный факт, что данные семельфактивы сочетаются с наречием медленно 3 . Примеры (16)-(18) свидетельствуют, с одной стороны, о том, что в семантической структуре данных глаголов сема моментальности и динамичности (сема 'быстро1') может отодвигаться на периферию, при этом центральную позицию занимает сема одноактности действия. Единичный, законченный акт представляется как длящийся процесс. С другой стороны, данные примеры показывают, что семельфактивы не обязательно содержат сему 'быстро’.

(16) Наконец он медленно шагнул и двинулся среди толпы прохожих и только через минуту сообразил, что идет все-таки вправо (Федор Кнорре. Продается детская коляска (1967) НКРЯ).

(17) Я тоже... пойду-уу. - Олежка медленно зевнул. Я поднялся с крыльца (Владимир Маканин. Неадекватен // «Новый Мир», 2002. НКРЯ).

(18) Варечка медленно глотнула и уставилась на него стеклянными глазами (Аркадий Стругацкий, Борис Стругацкий. Путь на Амальтею (1959) НКРЯ).

Семельфактивы с суффиксом -ну- могут быть дериватами глаголов гомогенного действия, ср. дуть-дунуть, глядеть-глянуть, ругать-ругнуть, пугать-пугнуть, курить-курнуть, тормозить-тормознуть и т. Д. Данные гла-

${ }^{3}$ O семантике наречия медленно см. подробнее в статье (Богуславский, Иомдин 2000). 
голы имеют более сложное семантическое поле, чем первый тип, поскольку кроме семы одноактности они содержат еще семы 'быстро1' и 'сильно', т. е. они указывают на выполнение интенсивного действия за краткое время (РГ-I 1980: 598; Плунгян 2011: 401), см. пример (19). С точки зрения словообразования связь таких глаголов с процессуальностью бесспорна, однако из этого не следует, что глаголы дуть и дунуть можно считать видовой парой. Если в позициях нейтрализации видовых значений мотивирующий глагол может заменить семельфактив, то можно предполагать, что данные глаголы также нельзя считать моментальными.

(19) Подняв воротник, сунув руки в карманы и оскальзываясь, водитель просеменил к дверям, а войдя, ругнул погоду, гололед и американские сигареть (А. Волос. Недвижимость (2000), НКРЯ).

(19б) Подняв воротник, сунув руки в карманы и оскальзываясь, водитель семенит к дверям, а войдя, ругает погоду, гололед и американские сигареты.

Однако нужно отметить, что глагол «ругает» не содержит семы 'сильно' и лишен стилистической окраски. В связи с этим возникает сомнение в том, что исходное предложение (19) и трансформ (19б) можно считать семантическими эквивалентами

В значении одноактного СД с суффиксом - $а н y$ - сема однократности сочетается с семой интенсивности, неожиданности. Все эти глаголы указывают на действие, проводимое «резко, с силой и грубо» (Зализняк, Шмелев 1997: 101). В контексте настоящего исторического глаголы теряют сему резкости (см. предложение (20б), поэтому можно предположить, что резать и резануть не являются видовыми коррелятами, следовательно, данный тип глаголов бесспорно можно считать моментальными глаголами.

(20) Спустя секунду она вспомнила, чья это машина, но что-то неприятно резануло глаз (М. Маринина. Смерть и немного любви, 13).

(20б) Спустя секунду она вспоминает, чья это машина, но что-то неприятно режет глаз.

По мнению венгерского аспектолога Й. Крекича, некоторые глаголы с приставкой про-, типа просвистеть, прозвонить, простучать, прошептать, проскрипеть, пробормотать передают значение протяженной однократности действия, т. е. они тоже указывают на выполнение одноактного действия за небольшой промежуток времени (Крекич 1997: 29). Заметим, что такое понимание отражается и в более ранних работах (Шелякин 1983: 189; 1987: 80 Бондарко 1987: 105), в которых данные глаголы называются представителями протяженно-одноактного СД. Описанная выше трактовка Й. Крекича позволяет установить, что в семантическом поле этих глаголов сема одноактности сочетается с семой 'быстро1', см. пример (21).

(21) Нара не успела закрыть рот, как кривой сосновый сук просвистел перед ее лицом (Александр Григоренко. Ильгет. Три имени судьбы // Урал, 2013. НКРЯ)

Некоторые глаголы с префиксально-суффиксальным образованием вз-/ вс- -нy-, типа всхрапнуть помимо одноактности содержат семы внезапности
Семантический анализ глаголов со значением быстрого действия в русском языке

и интенсивности действия - 'быстро1' Их семантика сближается с глаголами ингрессивного СД типа вскричать (Бондарко, Буланин 1967: 25; Зализняк, Шмелев 1997: 101), см. пример (22).

(22) Рената секунду посидела с разинутым ртом, потом истошно взвизгнула (Б. Акунин. Левиафан, 183)

\section{3. Итоги}

На основе проведенного исследования мы убедились в том, что сема 'быстро' может проявляться не только на лексическом и синтаксическом уровнях, но и на уровне морфологии тоже, т. е. она способна грамматикализоваться. Наш анализ позволяет прийти к следующим выводам:

1. Значение 'быстро', точнее значение 'быстро1' грамматикализуется суффиксами -ну-, -ану- и префиксом про-.

2. Значение 'быстро' несомненно связано с моментальностью, одноактностью и целостностью действия. Однако, как показали примеры, дефиниция моментальных глаголов нуждается в некотором уточнении.

3. Одноактность и повышенная скорость проведения действия не предполагают друг друга (см. возможность сочетаемости семельфактивов с наречием медленно), поэтому значение 'быстро’ можно считать связывающим звеном между моментальностью и процессуальностью.

Использованная литература

Апресян, Юрий Д. «Глаголы моментального действия и перформативы в русском языке». [В:] Ю. Н. Караулов (ред.). Русистика сегодня. Язык: система и его функционирование. Москва: Наука, 1988, 57-78.

Богуславский, Игорь М., Леонид Л. Иомдин. «Семантика быстроты». Вопросы языкознания 6, 1999: 13-30.

Богуславский, Игорь М., Леонид Л. Иомдин. «Семантика медленности». [В:] Л. Л. Иомдин, Л. П. Крысин (ред.). Слово в тексте и в словаре: Сборник статей к семидесятилетию академика Ю. Д. Апресяна. Москва: Язык русской культуры, 2000 , $52-60$.

Бондарко, Александр В., Лев. Л. Буланин. Русский глагол. Ленинград: Просвещение, 1967.

Бондарко, Александр В. «Основания функциональной грамматики» [В:] А. В. Бондарко (ред.). Теория функциональной грамматики. Введение Аспектуальность. Временная локализованность. Таксис. Ленинград: Наука, 1987, 98-123.

Горбова, Елена В. «Русские семельфактивы и непрототипическая алломорфия». Russian linguistics 40(1), 2016: 57-78.

Зализняк, Анна А., Алексей Д. Шмелев. Лекции по русской аспектологии. München Verlag Otto Sagner, 1997

Князев, Юрий П. «Мультипликативные предикаты: значение и форма». [В:] А. П. Володин (ред.). Типологические обоснования в грамматике: К 70-летию В. С. 
86

Илдико Палоши

Храковского. Москва: Знак, 2004, 216-223.

Крекич, Йожеф. Педагогическая грамматика русского глагола. Szeged: Tankönyvkiadó, 1997.

Маслов, Юрий С. «Вид и лексическое значение в русском языке». Изв. АН СССР Сер. лит. и яз. Т. 7., 4, 1948: 303-316.

Падучева, Елена В. «Семантические источники моментальности русского глагола в типологическом ракурсе». [В:] М. Ю. Черткова (ред.). Типология вида: проблемы, поиски, решения. Москва: Языки русской культуры, 1998, 332-342.

Плунгян, Владимир А. «“Быстро’ в грамматике русского и других языков». [В:] Л.

Л. Иомдин, Л. П. Крысин (ред.). Слово в тексте и в словаре: Сборник статей к семидесятилетию академика Ю. Д. Апресяна. Москва: Язык русской культуры, $2000,212-221$.

Плунгян, Владимир А. Введение в грамматическую семантику: грамматические значения и грамматические система языков мира. Учебное пособие. Москва: Изд-во РГГУ, 2011.

Шведова, Наталия Ю. (гл. ред.). Русская грамматика. Том І. Москва: Русский язык, 1980 [РГ-І 1980].

Шелякин, Михаил А. Категория вида и способы действия русского глагола. Таллин: Валгус, 1983.

Шелякин, Михаил А. «Способы действия в поле лимитативности». [В:] А. В. Бондарко (ред.). Теория функциональной грамматики. Введение. Аспектуальность. Временная локализованность. Таксис. Ленинград: Наука, 1987, 63-85.

Храковский, Виктор С. «Мультипликативы и семельфактивы (проблема видовой пары)». [В:] С. Кароляк (ред.). Семантика и структура славянского вида. Т. 2. Krakow: Wydawnictwo Naukowe WSP, 1997, 227-239.

Храковский, Виктор С. «Типология семельфактива». [В:] М. Ю. Черткова (ред.) Типология вида: проблемы, поиски, решения. Москва: Языки русской культуры, 1998, 485-490.

Илдико Палоши

\section{СЕМАНТИЧКА АНАЛИЗА ГЛАГОЛА СА ЗНАЧЕЬЕМ БРЗЕ РАДЬЕ У РУСКОМ ЈЕЗИКУ}

\section{Резиме}

У раду се разматрају (на материјалу руског језика) глаголи у чију семантичку зону спада и сема брзог вршења радње (рус.'быстро'). Основни циљ истраживања био је да се утврди семантички однос између моменталног (тренутног), једноактног, динамичког (брзог) и процесуалног карактера радње. Аутор је себи поставио задатак да пронађе одговоре на следећ

(1) Помоћу којих афикса се сема 'брзо' може граматикализовати?

(2) Са којим семама се сема ‘брзо’ може повезивати у семантичкој структури глагола?

(3) Каква је корелација између моменталног и брзог извршења радње?

На основу проведеног испитивања аутор закључује да сема 'брзо’ може да се манифестује не само на лексичком и синтаксичком већ и на морфолошком нивоу, што значи да је она спо-
Сеиачтический анализ глаголов со значениеи быстрого действия в русскои языне

собна да се граматикализује. Анализа корпусног материјала пружила је могућност да се дође до следећих, прецизнијих закључака (одговора на постављена питања):

(1) значење 'брзо' (тачније ‘брзо1') граматикализује се суфиксима -ну-, -ану- и префиксом про-;

(2) значење 'брзо' је несумњиво повезано са особинама моменталности, једноактности и целовитости ралње (уз напомену да дефинищија моменталних глагола, као што су примери показали, захтева одрећено додатно појашњење);

(3) једноактност / моменталност радње и повећана брзина њеног извршења не имплицирају једно друго (уп. могућност спојивости семелфактива са рус. прилогом медленно <'полако’>), због чега се значење ‘брзо’ може сматрати везивном кариком између моменталности и процесуалности.

Кључне речи: граматикализација, семелфактив, моменталност, динамичност, процесуалност. 